\title{
Adsorption of Anionic Dyes Using Monoionic and Binary Systems: a Comparative Study
}

\author{
Ahmed Zaghloul ${ }^{1}$, M'hamed Abali ${ }^{1}$, Abdeljalil Ait Ichou ${ }^{1}$, Ridouan Benhiti ${ }^{1}$, Amina Soudani ${ }^{2}$, Mohamed \\ Chiban 1,* (D), Mohamed Zerbet ${ }^{1}$, Fouad Sinan ${ }^{1, *}$ \\ 1 Laboratory LACAPE, Faculty of Science, University Ibn Zohr, BP. 8106, Hay Dakhla, Agadir, Morocco \\ 2 Faculty of Applied Sciences, University Campus Ait Melloul, Morocco \\ * Correspondence: f.sinan@uiz.ac.ma (F.S.); mmchiban@gmail.com (M.C.);
}

Scopus Author ID 55999934200 (F.S.) 12787642200 (M.C.)

Received: 17.12.2020; Revised: 10.01.2021; Accepted: 14.01.2021; Published: 20.01.2021

\begin{abstract}
Layered double hydroxide $\mathrm{Mg}_{2} \mathrm{Al}-\mathrm{LDH}$ with $\mathrm{Mg}^{2+} / \mathrm{Al}^{3+}$ molar ratio of 2 was prepared via urea method and used to remove two dyes, namely methyl orange (MO) and Congo red (CR) in monoionic and binary systems by batch adsorption. The results showed by X-ray diffraction analysis of $\mathrm{Mg}_{2} \mathrm{Al}-\mathrm{LDH}$ confirm the crystal structure of the $\mathrm{Mg}_{2} \mathrm{Al}-\mathrm{LDH}$ material. The adsorption of MO and CR in binary systems decreased in the case of the mixture, compared to MO and CR alone with 98 and 70\% of $\mathrm{MO}$ and $\mathrm{CR}$, respectively. According to this study's results, it could be concluded that $\mathrm{Mg}_{2} \mathrm{Al}-\mathrm{LDH}$ adsorbent can be used effectively to remove anionic dyes from industrial wastewater.
\end{abstract}

Keywords: monoionic and binary systems; anionic dyes; adsorption; wastewater treatment.

(C) 2020 by the authors. This article is an open-access article distributed under the terms and conditions of the Creative Commons Attribution (CC BY) license (https://creativecommons.org/licenses/by/4.0/).

\section{Introduction}

Because of their accumulation (in both effluents and the environment), the use of chemicals leads to serious environmental problems directly or indirectly (chronic toxicity). These issues arise from these compounds or their products of degradation. It is estimated that more than $7 \times 10^{5}$ tons and about 10000 different kinds of dyes and pigments are produced yearly worldwide. It is estimated that 10 to $15 \%$ of the dye is lost in effluents [1]. A wide range of techniques has been developed to remove dyes from wastewater, such as coagulation/flocculation [2,3], oxidation/ozonation [4], membrane separation [5,6], photodegradation [7] along with biological processes [8]. Adsorption is one of the most popular and widely practiced due to its low-cost, ease of operation, high efficiency and efficiency, and a wide range of implementation in various conditions [9]. Adsorption processes are reported as an effective and efficient method to decolorize wastewater. It involves the transfer of dye particles on the adsorbent, resulting in clearer effluent [10].

Layered double hydroxides (LDHs) are intensively investigated because of their high anionic exchange capacity [11], reuse, larger surface area, porosity, and fundamental properties [12]. They have advantages over commercially available adsorbents in terms of low cost, high adsorption properties, and non-toxicity. The use of LDH could bring significant economic and environmental benefits to the wastewater treatment industries [13].

To our knowledge, little is known about MO and CR's use for the adsorption of synthetic clay, hence the originality of this work. The main aim of this work was to investigate 
the adsorption of MO and CR onto the synthetic clay to evaluate the behavior of two dyes in mono-ionic and binary systems

\section{Materials and Methods}

\subsection{Preparation of methyl orange and Congo red dyes.}

Methyl orange and Congo red used in this study were purchased from Panreac (Barcelona, Spain). A Stock solution of $1 \mathrm{~g} . \mathrm{L}^{-1}$ in methyl orange and Congo red dyes were prepared with double-distilled water. The working solutions were obtained by diluting the stock solution. Table 1 shows the molecular structures and some physicochemical characteristics of used dyes

Table 1. Physicochemical characteristics of used methyl orange and Congo red dyes.

\begin{tabular}{l|c|c|c|c}
\multicolumn{1}{c|}{ Name (nm) } & Molecular structure & Nature & Molar mass (g. mol $\left.{ }^{-1}\right)$ & $\lambda_{\text {max }}$ \\
\hline Methyl Orange & Anionic & 327.3 & 464 \\
\hline Congo red & Anionic & 696.66 & 497
\end{tabular}

\subsection{Preparation and characterization of $\mathrm{Mg}_{2} \mathrm{Al}-\mathrm{LDH}$.}

The same conditions and experimental description from synthesized adsorbent $\mathrm{Mg}_{2} \mathrm{Al}-$ $\mathrm{LDH}$ were given in detail in previous reports $[1,14]$.

A detailed characterization of $\mathrm{Mg}_{2} \mathrm{Al}-\mathrm{LDH}$ adsorbent has been done using different techniques, as was described in our previous report. X-ray diffraction analysis of $\mathrm{Mg}_{2} \mathrm{Al}-\mathrm{LDH}$ confirms the crystal structure of the $\mathrm{Mg}_{2} \mathrm{Al}-\mathrm{LDH}$ material [1,15].

Figure 1 presents the SEM images of $\mathrm{Mg}_{2} \mathrm{Al}-\mathrm{LDH}$. The two images present the morphology of the platelets, which reflected a good crystallinity.
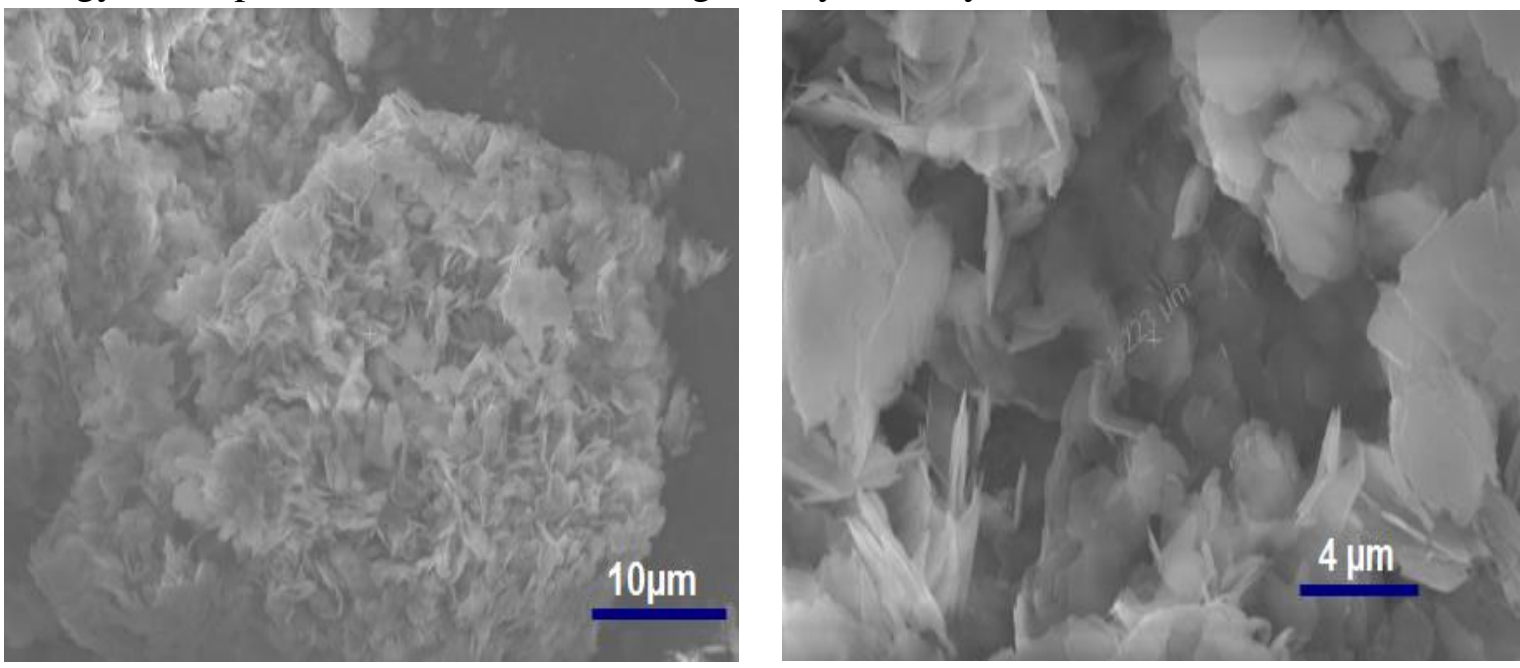

Figure 1. Scanning electron microscopy image of $\mathrm{Mg}_{2} \mathrm{Al}-\mathrm{LDH}$ material.

Figure 2 displays the infrared spectra of $\mathrm{Mg}_{2} \mathrm{Al}-\mathrm{LDH}$, the broad absorption at 3395 $\mathrm{cm}^{-1}$ is assigned to $\mathrm{O}-\mathrm{H}$ stretching of the water molecule in the brucite-like layers $[16,17]$, the 
weak band at $1632 \mathrm{~cm}^{-1}$ is due to the bending vibration (deformation mode of $\mathrm{H}-\mathrm{O}-\mathrm{H}(\mathrm{H}-\mathrm{O}-$ $\mathrm{H})$ ) of interlayer water molecules in LDH $[18,19]$. The stretching and bending modes of the $\mathrm{CO}_{3}{ }^{2-}$ group are observed at $1354 \mathrm{~cm}^{-1}$ [20]. The bands at $652-455 \mathrm{~cm}^{-1}$ regions are ascribed to M-oxygen-M stretching ( $\mathrm{M}=\mathrm{Mg}$ and $\mathrm{Al})[21,13]$.

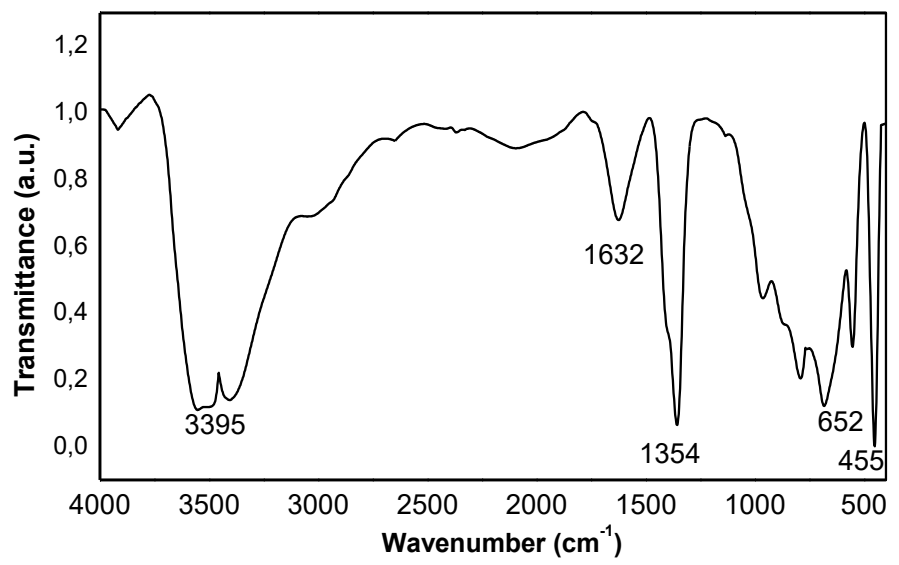

Figure 2. FTIR spectra of $\mathrm{Mg}_{2} \mathrm{Al}-\mathrm{LDH}$.

\subsection{Batch studies.}

The adsorption of methyl orange (MO) and Congo Red (CR) onto synthetic clay in monoionic and binary systems was carried out in a batch system. The adsorption of two dyes was carried out in a thermostatic bath by adding $0.02 \mathrm{~g}$ of our adsorbent into a flask containing $40 \mathrm{~mL}$ of the mixture of two dyes $(\mathrm{MO}+\mathrm{CR})$ by varying the contact time $(1-180 \mathrm{~min})$ and composition dye (90\% MO+10\% CR;70\% MO $\%+30 \% \mathrm{CR} ; 50 \% \mathrm{MO}+50 \% \mathrm{CR} ; 70 \% \mathrm{CR} \%$ $+30 \% \mathrm{MO} ; 90 \% \mathrm{CR}+10 \% \mathrm{MO})$. After a suitable time, the dye solution was separated from the adsorbent by centrifugation for $15 \mathrm{~min}$ at $3000 \mathrm{rpm}$.

In monoionic system, the percentage removal of dyes adsorbed at equilibrium was given by the following equation:

$$
\text { Removal efficiency }(\%)=\frac{\left(\boldsymbol{C}_{0}-\boldsymbol{C}_{\boldsymbol{e}}\right)}{\mathbf{C}_{\mathbf{0}}} \times 100
$$

where $\mathrm{C}_{0}$ and $\mathrm{C}_{\mathrm{e}}$ are the initial and equilibrium concentration $\left(\mathrm{mg} . \mathrm{L}^{-1}\right)$ of dyes in solution.

In a binary mixture of $A$ and $B$ components, the optical densities $\mathrm{d}_{1}$ and $\mathrm{d}_{2}$ were measured at $\lambda_{1}$ and $\lambda_{2}[22]$.

$$
\begin{aligned}
C_{A} & =\frac{k_{22} d_{1}-k_{21} d_{2}}{k_{11} k_{22}-k_{12} k_{21}} \\
C_{B} & =\frac{k_{11} d_{2}-k_{12} d_{1}}{k_{11} k_{22}-k_{12} k_{21}}
\end{aligned}
$$

\section{Results and Discussion}

\subsection{Adsorption of MO and CR in monoionic system.}

Figure 3 shows the adsorption kinetics in $\mathrm{MO}$ and $\mathrm{RC}$ by $\mathrm{Mg}_{2} \mathrm{Al}-\mathrm{LDH}$ at $100 \mathrm{mg} . \mathrm{L}^{-1}$. The equilibrium was reached after $15 \mathrm{~min}$ for $\mathrm{MO}$ and $120 \mathrm{~min}$ for $\mathrm{CR}$, with percentage removal 98 and $70 \%$ for $\mathrm{MO}$ and $\mathrm{CR}$, respectively. 

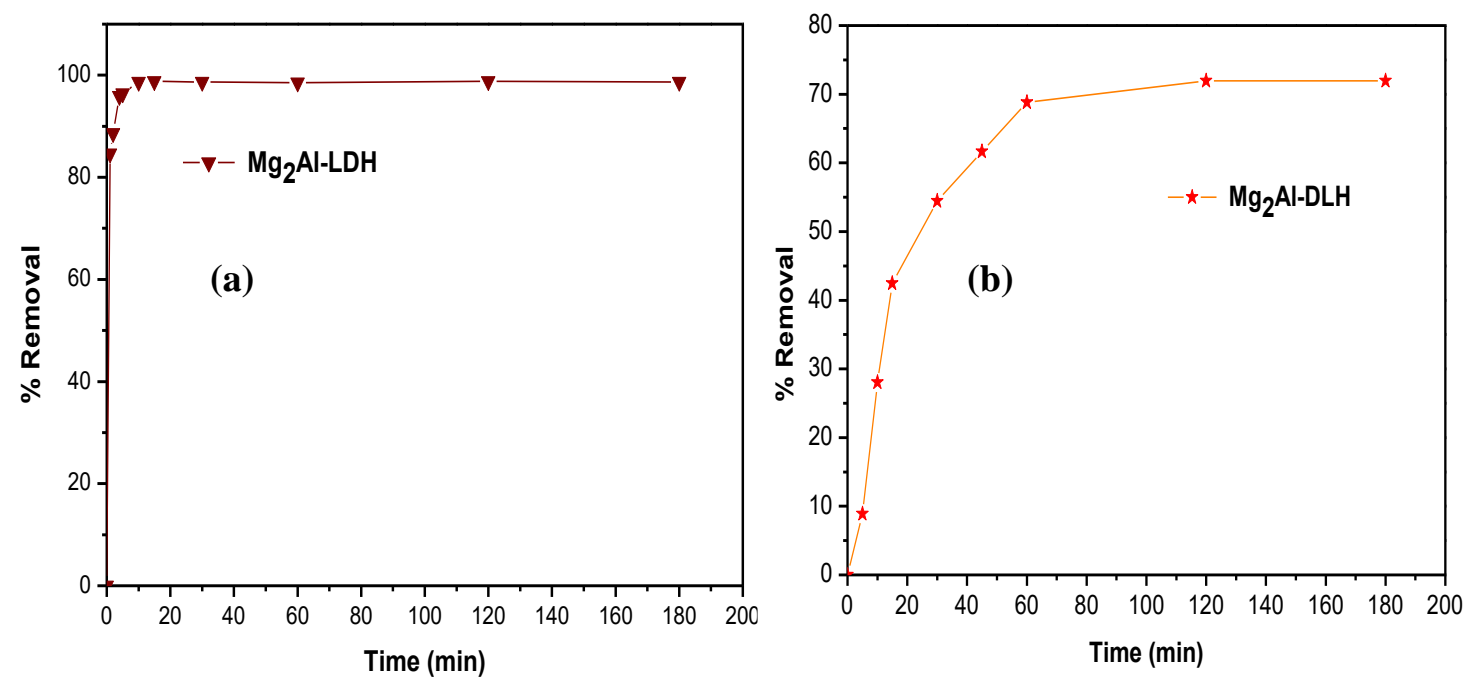

Figure 3. Adsorption kinetics in (a) MO; (b) RC by monoionic system.

\subsection{Adsorption dyes in a binary mixture.}

\subsubsection{Calibration curve.}

The calibration curves of MO and CR at maximum wavelengths: 464 and $497 \mathrm{~nm}$. These curves allow us to determine the calibration constants (Figure 4).
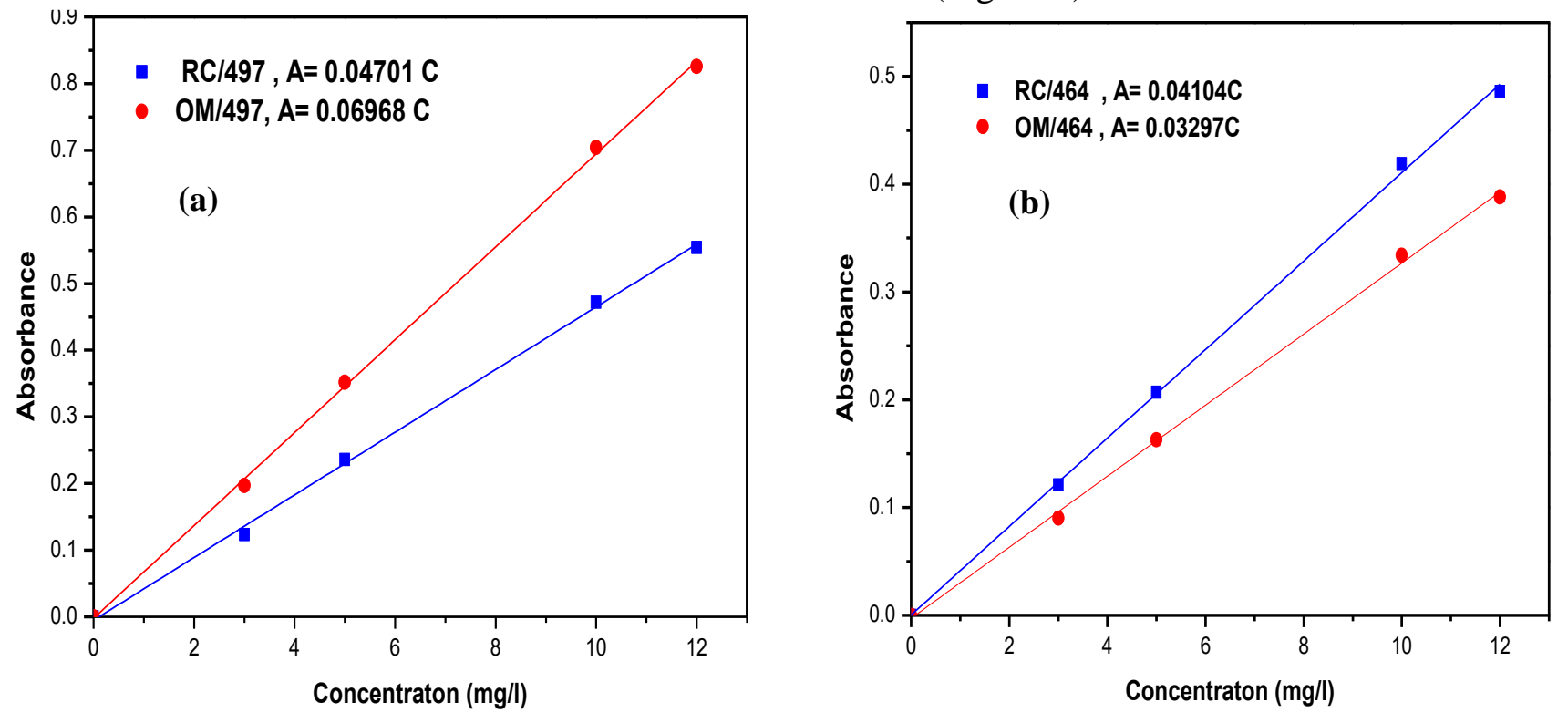

Figure 4. Calibration curve of MO and CR; (a) $\lambda_{\max }=497 \mathrm{~nm} ;$ (b) $\lambda_{\max }=464 \mathrm{~nm}$.

\subsubsection{Adsorption of $\mathrm{MO}$ and $\mathrm{CR}$ in a binary system.}

The adsorption of MO and CR dyes onto synthetic clay in a binary system (MO + CR) comparing with the same dyes taken individually has been investigated by varying the percentage of $\mathrm{MO}$ and $\mathrm{CR}$ in the binary mixture with the adsorbent dose, the initial dye concentration and the contact time have been fixed at $0.5 \mathrm{~g} . \mathrm{L}^{-1}, 100 \mathrm{mg} . \mathrm{L}^{-1}$ and $180 \mathrm{~min}$ respectively, At the room temperature and the initial dye solution $\mathrm{pH}$. The obtained results are illustrated in Figure 5. While analyzing these results, we noticed that MO and CR's adsorption decreased in the case of mixing, compared to MO and CR alone. This could be explained by the competitive effect between the two anionic dyes. 


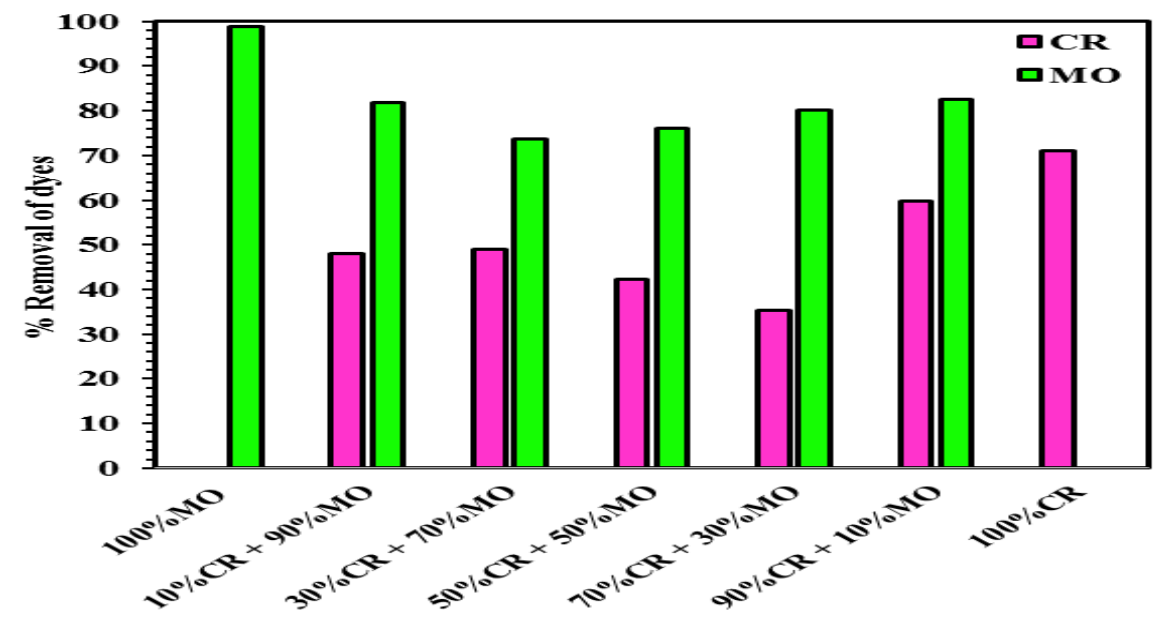

Figure 5. Adsorption of MO and CR in binary systems.

\section{Conclusions}

In this study, adsorption experiments for removing methyl orange and Congo red from aqueous solutions were performed using monoionic and binary systems. The results also show that these materials were found to be excellent adsorbent for the MO and CR. The adsorption of MO and CR in binary systems decreased in the case of mixing, compared to MO and CR alone. These exciting results offer several perspectives, such as recycling the material used; the synthesized carrier is also be tested for trapping other organic solvents.

\section{Funding}

This research received no external funding.

\section{Acknowledgments}

This research has no acknowledgment.

\section{Conflicts of Interest}

The present paper is an original work, and all the authors declare that they have no conflicts of interest

\section{References}

1. Zaghloul, A.; Benhiti, R.; Soudani, A.; Chiban, M.; Zerbet, M.; Sinan, F. Removal of methyl orange from aqueous solution using synthetic clay type MgAl-LDH: Characterization, Isotherm and thermodynamic studies. Mediterranean Journal of Chemistry 2019, http://dx.doi.org/10.13171/mjc92190925728fs

2. Panswad, T.; Wongchaisuwan, S. Mechanisms of Dye Wastewater Colour Removal by Magnesium Carbonate-Hydrated Basic. Water Science and Technology 1986, 18, 139-144, https://doi.org/10.2166/wst.1986.0045.

3. Sureshkumar, M.V.; Namasivayam, C. Adsorption behavior of Direct Red 12B and Rhodamine B from water onto surfactant-modified coconut coir pith. Colloids and Surfaces A: Physicochemical and Engineering Aspects 2008, 317, 277-283, https://doi.org/10.1016/j.colsurfa.2007.10.026.

4. Malik, P.K.; Saha, S.K. Oxidation of direct dyes with hydrogen peroxide using ferrous ion as catalyst. Separation and Purification Technology 2003, 31, 241-250, https://doi.org/10.1016/S1383-5866(02)002009 
5. Ciardelli, G.; Corsi, L.; Marcucci, M. Membrane separation for wastewater reuse in the textile industry. Resources, Conservation and Recycling 2001, 31, 189-197, https://doi.org/10.1016/S0921-3449(00)00079-3

6. Tan, K.B.; Vakili, M.; Horri, B.A.; Poh, P.E.; Abdullah, A.Z.; Salamatinia, B. Adsorption of dyes by nanomaterials: Recent developments and adsorption mechanisms. Separation and Purification Technology 2015, 150, 229-242, https://doi 10.1016/j.seppur.2015.07.009.

7. Gardiner, D.K.; Borne, B.J. Textile Waste Waters: Treatment and Environmental Effects. Journal of the Society of Dyers and Colourists 1978, 94, 339-348, https://doi.org/10.1111/j.1478-4408.1978.tb03420.x.

8. Ledakowicz, S.; Solecka, M.; Zylla, R. Biodegradation, decolourisation and detoxification of textile wastewater enhanced by advanced oxidation processes. Journal of Biotechnology 2001, 89, 175-184, https://doi.org/10.1016/S0168-1656(01)00296-6.

9. Anastopoulos, I.; Margiotoudis, I.; Massas, I. The use of olive tree pruning waste compost to sequestrate methylene blue dye from aqueous solution. International Journal of Phytoremediation 2018, 20, 831-838, https://doi.org/10.1080/15226514.2018.1438353.

10. Salim, S.d.; Hadibarata, T.; Elwina, E.; Dewi, R.; Alaraidh, I.A.; Al-Ghamdi, A.A.; Alsahli, A.A. Development of activated carbon from Eichhornia Crassipes via chemical activation and its application to remove a synthetic dye. Biointerface Research in Applied Chemistry 2019, 9, 4394-4400, https://doi.org/10.33263/BRIAC95.394400.

11. Ni, Z.-M.; Xia, S.-J.; Wang, L.-G.; Xing, F.-F.; Pan, G.-X. Treatment of methyl orange by calcined layered double hydroxides in aqueous solution: Adsorption property and kinetic studies. Journal of Colloid and Interface Science 2007, 316, 284-291, https://doi.org/10.1016/j.jcis.2007.07.045.

12. Li, F.; Wang, Y.; Yang, Q.; Evans, D.G.; Forano, C.; Duan, X. Study on adsorption of glyphosate (Nphosphonomethyl glycine) pesticide on MgAl-layered double hydroxides in aqueous solution. Journal of Hazardous Materials 2005, 125, 89-95, https://doi.org/10.1016 / j.jhazmat.2005.04.037.

13. Zubair, M.; Jarrah, N.; Ihsanullah; Khalid, A.; Manzar, M.S.; Kazeem, T.S.; Al-Harthi, M.A. Starch-NiFelayered double hydroxide composites: Efficient removal of methyl orange from aqueous phase. Journal of Molecular Liquids 2018, 249, 254-264, https://doi.org/10.1016/j.molliq.2017.11.022.

14. Benhiti, R.; Ait Ichou, A.; Zaghloul, A.; Aziam, R.; Carja, G.; Zerbet, M.; Sinan, F.; Chiban, M. Synthesis, characterization, and comparative study of MgAl-LDHs prepared by standard coprecipitation and urea hydrolysis methods for phosphate removal. Environmental Science and Pollution Research 2020, 27, 4576745774, https://doi.org/10.1007/s11356-020-10444-5.

15. Chakraborty, A.; Acharya, H. Facile Synthesis of MgAl-Layered Double Hydroxide Supported Metal Organic Framework Nanocomposite for Adsorptive Removal of Methyl Orange Dye. Colloid and Interface Science Communications 2018, 24, 35-39, https://doi.org/10.1016/j.colcom.2018.03.005.

16. Aisawa, S.; Hirahara, H.; Uchiyama, H.; Takahashi, S.; Narita, E. Synthesis and Thermal Decomposition of Mn-Al Layered Double Hydroxides. Journal of Solid State Chemistry 2002, 167, 152-159, https://doi.org/10.1006/jssc.2002.9637.

17. Shamsayei, M.; Yamini, Y.; Asiabi, H. Fabrication of zwitterionic histidine/layered double hydroxide hybrid nanosheets for highly efficient and fast removal of anionic dyes. Journal of Colloid and Interface Science 2018, 529, 255-264, https://doi.org/10.1016/j.jcis.2018.06.022.

18. Kang, H.T.; Lv, K.; Yuan, S.L. Synthesis, characterization, and SO2 removal capacity of MnMgAlFe mixed oxides derived from hydrotalcite-like compounds. Applied Clay Science 2013, 72, 184-190, https://doi.org/10.1016/j.clay.2013.01.015.

19. Ichou, A.A.; Benhiti, R.; Abali, M.; Dabagh, A.; Chiban, M.; Zerbet, M.; Carja, G.; Sinan, F. Adsorption of $\mathrm{Pb}$ (II) from aqueous solutions onto MgFeAl-CO3 LDH: thermodynamic and kinetic studies. DESALINATION AND WATER TREATMENT 2020, 178, 193-202, https://doi.org/10.5004/dwt.2020.24952.

20. Ferreira, O.P.; Alves, O.L.; Gouveia, D.X.; Souza Filho, A.G.; de Paiva, J.A.C.; Filho, J.M. Thermal decomposition and structural reconstruction effect on $\mathrm{Mg}-\mathrm{Fe}-$ based hydrotalcite compounds. Journal of Solid State Chemistry 2004, 177, 3058-3069, https://doi.org/10.1016/j.jssc.2004.04.030.

21. Zaghouane-Boudiaf, H.; Boutahala, M.; Arab, L. Removal of methyl orange from aqueous solution by uncalcined and calcined MgNiAl layered double hydroxides (LDHs). Chemical Engineering Journal 2012, 187, 142-149, https://doi.org/10.1016/j.cej.2012.01.112.

22. Namasivayam, C.; Kavitha, D. Removal of Congo Red from water by adsorption onto activated carbon prepared from coir pith, an agricultural solid waste. Dyes and Pigments 2002, 54, 47-58, https://doi.org/10.1016/S0143-7208(02)00025-6. 